\title{
Invasive non-typhoidal salmonellosis
}

INSERM

\section{Source}

INSERM. (1999). Orphanet: an online rare disease and orphan drug data base. Invasive non-typhoidal salmonellosis. ORPHA:324648

Invasive non-typhoidal salmonellosis is a rare, bacterial, infectious disease caused by extraintestinal infection of non-typhoidal serotypes of Salmonella enterica in patients with underlying HIV infection, malaria or malignancy. It has a high mortality rate and patients typically present with fever, pallor and respiratory signs (cough, tachypnea, pneumonia). Gastrointestinal manifestations (diarrhea, vomit, abdominal pain) are not common. Occasionally, organ abscesses, septic shock and mening itis may be observed. 